\title{
Three-factor structure of self-report schizotypal traits in a French nonclinical sample
}

\author{
Jérôme Brunelin ${ }^{1,2 *}$, Patrick Dumas ${ }^{1}$, Mohamed Saoud ${ }^{1,2}$, Thierry d'Amato ${ }^{1,2}$, Emmanuel Poulet ${ }^{1,2}$
}

${ }^{1} \mathrm{CH}$ Le Vinatier, Bron, France;

${ }^{2}$ Université de Lyon, Lyon, France; Université Lyon 1, Lyon, France; Bron, France.

Email: ${ }^{*}$ jerome.brunelin@ch-le-vinatier.fr

Received 6 June 2011; revised 10 July 2011; accepted 18 July 2011.

\begin{abstract}
Evidence suggests that the structure of psychosisproneness in the general population may involve three distinct related dimensions. Therefore we conducted a study, using a wider range of measures, to explore the factorial structure of schizotypy assessed by a mixed self-report Schizotypal Traits Questionnaire (mSTQ) in young French healthy individuals. Raine's Schizotypal Personality Questionnaire [SPQ] and four of the Chapman's scales [Magical Ideation Scale-MIS; Perceptual Aberration Scale-PAS; Revised Physical Anhedonia Scale-PhA and Revised Social Anhedonia Scale-SA] were combined to form a mSTQ which was administered to 232 French undergraduate students aged from 18 to 25 years old. A Principal Component Analysis [PCA] was carried out on scores for each scale to examine the factorial structure of schizotypal traits in this sample. PCA evidenced a three-factor model of schizotypy in the sample as a whole and even in the lower score subsample. The three factors were "positive or cognitiveperceptual", "negative or social-interpersonal" and “disorganization” latent. Schizotypy, as assessed by these scales, is a multidimensional construct composed by at least three dimensions in this nonclinical sample. This factorial structure is similar to those of schizophrenia symptoms which raise the hypothesis of a continuum from normality to schizophrenia via schizotypal traits
\end{abstract}

Keywords: Schizotypy; Psychosis Proneness Scales; Schizotypal Personality Questionnaire; Three-Factor Structure; Schizophrenia

\section{INTRODUCTION}

Many researchers acknowledges the existence of a schizophrenia spectrum, from normality to psychosis, of which schizophrenia is considered to be one extreme. Recognition of a schizophrenia spectrum received impetus from the genetic "high-risk" approach of studying the relatives of patients with schizophrenia [1,2]. Another strategy consists in the study of psychotic-like traits in the general population [3-5] through the development of schizotypy and psychosis-proneness scales [6-8] stemmed from the idea that traits which may predispose to schizophrenia can be identified in non-clinical populations [9]. However, schizophrenia itself can no longer be viewed as a unitary construct; rather there is a growing consensus that the clinical symptoms seem to cluster into at least three distinct syndromes [10-12]. In turn, schiz-otypy in non clinical samples has been shown to have a similar dimensional structure, with factors resembling at least 3 dimensions of schizophrenia: positive, negative, and cognitive-disorganisation $[3,4,13]$. However, some authors have evoked the possible influence of sociocultural context in schizotypal construct [14].

The aim of the present study was to look at schizotypal symptoms factorial structure in a French non clinical sample as measured by a mixed Schizotypal Traits Questionnaire (mSTQ). Factor analyses were conducted on a sample of undergraduate students. It was expected that the factors usually identified in schizophrenia and in studies using the SPQ: Schizotypal Personnality Questionnaire in other population $[4,15]$ would appear; namely, a factor that predominantly reflects positive symptoms, a factor that predominantly reflects negative symptoms, and a disorganized factor, suggesting a continuum from normal to psychosis.

\section{METHOD}

\subsection{Subjects}

Non clinical undergraduate students $(n=232)$ of both genders $($ Females $=125$; Males $=107)$, from 18 to 25 years old (Age \pm standard deviation: $21.17 \pm 1.47$ ), were 
recruited through campus public advertising which called for "a 50 euros paid study on character traits and personality”. Written informed consent was obtained from all participants and the study was approved by the Ethical Committee of Lyon B. All participants were free of serious somatic illness (including diabetes and neurological disorders), mood disorder, suicidal risk and of DSM-IV axis I psychotic personal history as explored through SADS examination [16]; none of them had ever received antipsychotic or antidepressant medications. Moreover, because of the genetic part of schizophrenia, subjects with family history of schizophrenia were not included in the study. Subjects with current or past history of substance abuse were not included in this study. However, knowing relationship between cannabis and schizotypal traits [17], cannabis consumers were included.

\subsection{Psychometric Investigations}

Among various instruments proposed to measure Schizotypal traits in clinical and non clinical samples, we have chosen five French-version [18-21] separate selfreport scales widely used in this field.

- Four of the Psychosis Proneness Scales [PPS] developed by Chapman and colleagues to measure traits known to be more frequent in subjects who later developed psychotic disorders, i.e.: The Magical Ideation Scale [MIS] [18,19] measures the acceptance of causal relationships not widely held by the dominant culture (e.g. "at times I perform certain little rituals to ward off negative influences”); the Perceptual Aberration Scale [PAS] [18,19] measures body image and object-related perceptual distortions (e.g. "at times I have wondered if my body was really my own”), the revised Physical Anhedonia Scale [PhA] [20,21] measures a lack of responsiveness to sensory experiences (e.g. "I have had very little desire to try new kinds of food”) and the Revised Social Anhedonia Scale [SA] [21] reflects the negative aspects of psychosis, and consists of items assessing the lack of enjoyment from social contact, physical activities, coupled with aversion to emotional and physical intimacy (e.g., "Are you much too independent to get involved with other people?").

- The Schizotypal Personality Questionnaire [SPQ] $[22,23]$ which contains 74 items evaluating the nine SPD DSM-IV criteria leading to a total score and nine possible sub-scores (Ideas of reference; Excessive social anxiety; Odd beliefs or magical thinking; Unusual perceptual experiences; Odd or eccentric behavior; No close friends; Odd speech; Constricted affect; Suspiciousness). These allow both categorical and dimensional approaches of Schizotypal Personality Disorder.

Participants have to check all the 240 items of the 5 scales. Items were presented in a in a combined order [24] as a mixed Schizotypal Traits Questionnaire (mSTQ). To limit the risk of contamination of questionnaire responses by drug effects, we instructed subjects not to report drug-related experiences when they completed the questionnaires.

\subsection{Statistical Analysis}

Pearson correlations were used to examine relationships between scores on PPS and SPQ sub-scales. Then, scores of the 232 participants on the SPQ sub-scales, PAS, MIS, $\mathrm{PhA}$ and SA were subjected to Principal Component Analysis (PCA). The number of extracted factors was decided using Kaiser's criteria and the Cattell's scree test before subsequent VARIMAX rotation. Then, an exploratory factor analysis of the SPQ sub-scales, PAS, MIS, PhA and SA was conducted with only the low scorers (n $=183$ ), identified as subjects who scored under the cut-off score on one or more of the five psychometric scales (Scale-lower cut-off score $-\mathrm{n}=$; PAS $-3 / 35-\mathrm{n}$ $=82 ; \mathrm{MIS}-5 / 30-\mathrm{n}=87 ; \mathrm{PhA}-9 / 61-\mathrm{n}=78 ; \mathrm{SA}$ $-7 / 40-n=80$; and SPQ-7/74-n = 29; see $[19,23]$ for more information about cut-off score calculation).

\section{RESULTS}

PCA has been carried out on the correlation matrix for scores at each PPS and each of the nine SPQ subscales. PCA revealed three factors with an eigenvalue of 1 or greater. The model accounted for $65.4 \%$ of the variance.

The first factor, which consisted of MIS, PAS, and four SPQ subscales ("Suspiciousness", "Odd or eccentric behavior”, "Unusual perceptual experiences”, and "Ideas of reference") accounted for $39.1 \%$ of the total variance. This factor is clearly consistent with a positive syndrome factor.

The second component, which consisted of SA, PhA, and three SPQ subscales evaluating "Excessive social anxiety", "No close friends" and "Constricted affect", accounted for $18.1 \%$ of the total variance. This factor is predominantly a negative syndrome factor.

The third component accounted for $8.2 \%$ of the total variance and consisted of the "Odd speech" SPQ subscale scores. This factor is most consistent with disorganization.

An exploratory factor analysis of the SPQ, PAS, MIS, PhA and SA was conducted on just the low scorers, identified as any student who scored under the cut-off score on any of the five scales $(n=183)$. The PCA again revealed the same 3 factors with an eigenvalue of 1 or greater (see Table 1). 


\section{DISCUSSION}

The present study aimed, to explore the factorial structure of schizotypal traits in young French healthy individuals by the mean of self-report scales. PCA yielded three factors that paralleled highly with previously reported factors; namely, negative or social-interpersonal factor (i.e. "Excessive social anxiety", "No close friends", and "Constricted affect", and Physical and Social anhedonia), positive or cognitive-perceptual (i.e. "Magical ideation”, "Perceptual aberration”, "Unusual perceptual experiences”, "Ideas of reference", "Suspiciousness", and "Odd or eccentric behavior") and disorganization (i.e. "Odd speech"). Strikingly, factor analyses with only the nonclinical low scorers revealed the same three-factors too, thus supporting the

Table 1. Percentage of total variance and factor solution for the 9 subscales of the schizotypal personality questionnaire (SPQ), the perceptual aberration scale (PAS), the magical ideation scale (MIS), the revised physical anhedonia scale (PhA), and the revised social anhedonia scale (SA) using the total sample $(\mathrm{n}=232)$ and the low scorers $(\mathrm{n}=183)$.

\begin{tabular}{|c|c|c|c|c|c|c|}
\hline \multirow[b]{3}{*}{$\begin{array}{l}\text { Percentage of } \\
\text { total variance }\end{array}$} & \multicolumn{3}{|c|}{ Total sample $(\mathrm{n}=232)$} & \multicolumn{3}{|c|}{ Low scorers $(\mathrm{n}=183)$} \\
\hline & \multicolumn{6}{|c|}{ Factor 1 Factor 2 Factor 3 Factor 1 Factor 2 Factor 3} \\
\hline & 39.1 & 18.1 & 8.2 & 33.2 & 17.4 & 8.8 \\
\hline $\begin{array}{l}1 \text { Ideas of } \\
\text { Reference (SPQ) }\end{array}$ & 0.821 & -0.182 & 0.073 & 0.768 & -0.159 & -0.165 \\
\hline $\begin{array}{l}2 \text { Excessive Social } \\
\text { Anxiety (SPQ) }\end{array}$ & 0.486 & 0.320 & 0.359 & 0.354 & 0.369 & -0.253 \\
\hline $\begin{array}{l}3 \text { Odd Beliefs or } \\
\text { Magical thinking } \\
\text { (SPQ) }\end{array}$ & 0.574 & -0.541 & -0.313 & 0.572 & -0.5 & 0.404 \\
\hline $\begin{array}{l}4 \text { Unusual Percep- } \\
\text { tual Experiences } \\
\text { (SPQ) }\end{array}$ & 0.788 & -0.348 & -0.098 & 0.788 & -0.243 & 0.062 \\
\hline $\begin{array}{l}5 \text { Odd or Eccentric } \\
\text { Behavior (SPQ) }\end{array}$ & 0.716 & 0.040 & 0.137 & 0.632 & 0.199 & -0.169 \\
\hline $\begin{array}{l}6 \text { No Close Friends } \\
\text { (SPQ) }\end{array}$ & 0.464 & 0.680 & -0.121 & 0.330 & 0.712 & 0.137 \\
\hline $\begin{array}{l}7 \text { Odd Speech } \\
\text { (SPQ) }\end{array}$ & 0.526 & -0.074 & 0.458 & 0.479 & -0.085 & -0.478 \\
\hline $\begin{array}{l}8 \text { Constricted } \\
\text { Affect (SPQ) }\end{array}$ & 0.527 & 0.577 & 0.264 & 0.414 & 0.663 & -0.226 \\
\hline $\begin{array}{l}9 \text { Suspiciousness } \\
\text { (SPQ) }\end{array}$ & 0.713 & 0.171 & 0.179 & 0.633 & 0.221 & -0.126 \\
\hline 10 PAS & 0.791 & -0.214 & -0.218 & 0.751 & -0.202 & 0.22 \\
\hline 11 MIS & 0.775 & -0.382 & -0.248 & 0.765 & -0.322 & 0.266 \\
\hline $12 \mathrm{PhA}$ & 0.029 & 0.593 & -0.509 & -0.218 & 0.459 & 0.523 \\
\hline $13 \mathrm{SA}$ & 0.448 & 0.657 & -0.330 & 0.376 & 0.634 & 0.387 \\
\hline
\end{tabular}

continuity view of psychosis and the multidimensionality of psychosis-proneness (Figure 1). These findings further replicate and support the three-factor model of schizotypal personality, as measured by the SPQ and PPS, in non clinical undergraduates students. These results also support previous findings suggesting that different proneness and schizotypal traits scales relate to different underlying aspects of schizophrenia [7].

Some methodological issues should be considered that may have influenced our results. First, subjects were not randomly selected leading to a possible concentration of pathological individuals. However, this bias was limited because subjects were clearly informed that no diagnosis would be delivered; Moreover, the study was very attractive for every students given they were paid for participation. Second, schizotypy was evaluated only through self-report scales leading to a possible misestimating of some schizotypal traits like oddness, although the use of a combined scale diminishes this bias. Conversely,
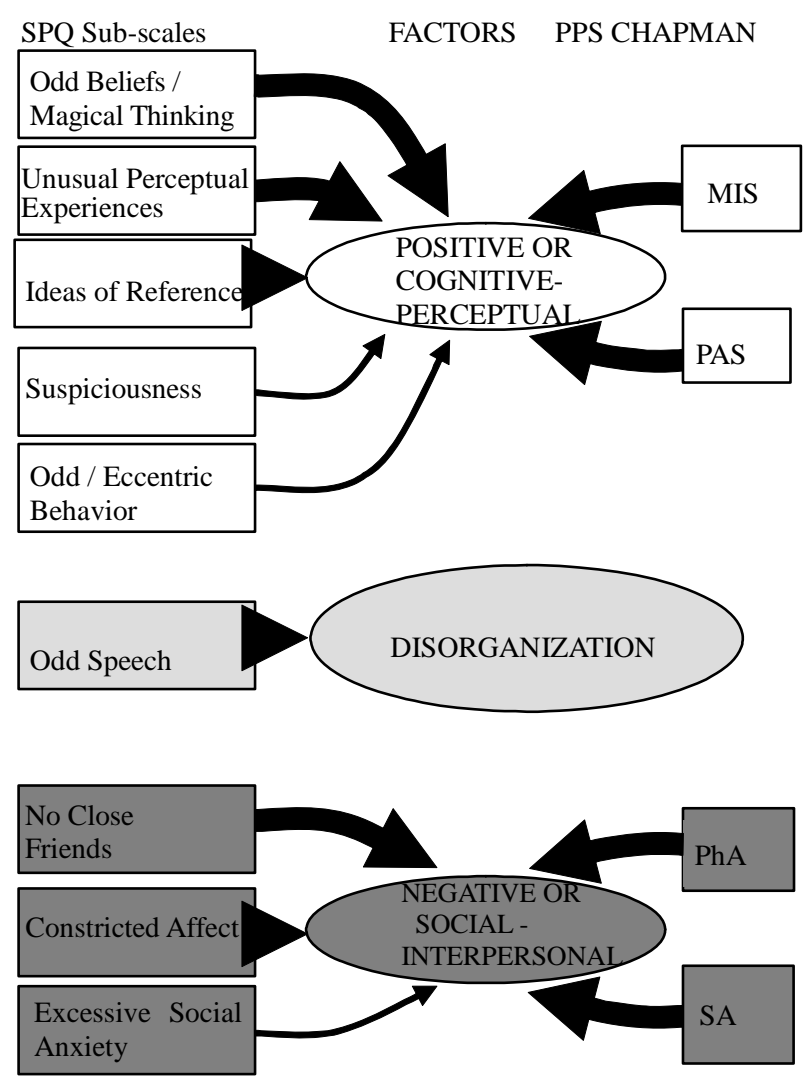

Figure 1. Path diagram illustrating the three factor structure of self-report schizotypy in a nonclinical sample of 232 students SPQ = schizotypal personality questionnaire; PPS = psychosis proneness scales; PAS = perceptual aberration scale; MIS = magical ideation scale; $\mathrm{PhA}=$ physical anhedonia scale; $\mathrm{SA}=$ social anhedonia scale. Observed variables are represented by squares, latent factors by circles. Single-headed arrows represent factor loadings. 
this method limits the rater's subjectivity. On the other hand, one can hypothesize that analysing of other proneness scales would permit the discrimination of other factors seen in schizophrenia like anxiety/depression or impulsivity/excitation [12]. Finally, as previously reported [17], our sample could be divided into three groups according to cannabis use typology: those who had never used cannabis $(n=126)$, those who were past or occasional users $(n=65)$, and those who were regular users $(n=41)$. Higher scores on the SPQ and the MIS were characterized by regular and past or occasional users compared with those who had never used cannabis. The fact that lower scorers were also non cannabis users is in accordance with recent report that the onset of schizotypal symptoms generally precedes the onset of cannabis use [25].

These remarks being taken into account, the results of the present study are consistent with prior research. Indeed, researchers have devised many questionnaires and structured interviews to measure schizotypal traits and, when various combinations of these measures have been subjected to factor analytic procedures, with either normal or clinical samples, three factors generally emerge [4,9,13,15,26-28]. Moreover, this three-factor model of schizotypal personality seems invariant across age and gender [29]. An alternative, four-factor model was suggested by the results of several large-scale factor-analytic studies of psychosis-proneness scales [3,24,30] or of other scales [31]. Nevertheless, most studies are based on measures of schizotypal symptoms given to non- clinical groups, mostly undergraduates and few studies have done factor analyses with non-normal samples. However, factor analyses with schizotypal and other clinical samples also support a three-dimensional model, though a paranoid [32,33] or an impulsivity [31] dimension is sometimes also seen. Although findings differ in detail across analyses, they appear to converge on the three-factor solution both in clinical and non-clinical samples. In a theoretical conceptualization of dimensionality in schizophrenia, a continuum of behaviors from normal to schizophrenic was often suggested (for review see [5]). Strikingly enough, in accordance with this continuum hypothesis, three-factor structure was also showed in the low scores sample. Interestingly, as with schizophrenia, the evidence for dimensionality in schizotypy is primarily found in factor analytic studies and the three schizotypal dimensions were close to some schizophrenic dimensions.

Our results suggest that schizotypal traits in a French non clinical sample, as measured with SPQ, MIS, PAS, $\mathrm{PhA}$, and SA, are a three-dimensional construct as seen in schizophrenia itself and in people with Schizotypal Personality Disorder. Future studies should examine the stability of those three schizotypal dimensions over time, by following schizotypal subjects well into the age of potential onset of schizophrenia. Moreover, questionnaires and structured interviews to measure schizotypal characteristics may take into account these factors.

\section{ACKNOWLEDGEMENTS}

This research was supported by grants from the "Progamme Hospitalier de Recherche Clinique” (PHRC), the "Université Lyon 1” (BQR) and the "Conseil Scientifique de la Recherche, CH Le Vinatier". The authors are grateful to T.R. Kwapil and A. Raine for their comments and their agreement about the French versions of their scales; to P. Dumas for the scales' translations and to F. Comte for technical help.

\section{REFERENCES}

[1] Saoud, M., d'Amato, T., Gutknecht, C., Triboulet, P., Bertaud, J.P., Marie-Cardine, M., Dalery, J. and Rochet, T. (2000) Neuropsychological deficit in siblings discordant for schizophrenia. Schizophrenia Bulletin, 26, 893902.

[2] Brunelin, J., d’Amato, T., Brun, P., Bediou, B., Kallel, L., Senn, M., Poulet, E. and Saoud, M. (2007) Impaired verbal source monitoring in schizophrenia: An intermediate trait vulnerability marker? Schizophrenia Research, 89, 287-292. doi:10.1016/j.schres.2006.08.028

[3] Claridge, C., McCreery, C., Mason, O., Bentall, R., Boyle, G., Slade, P. and Popplewell, D. (1996) The factor structure of schizotypal traits: A large replication study. British Journal of Clinical Psychology, 35, 103-115. doi:10.1111/j.2044-8260.1996.tb01166.x

[4] Raine, A., Reynolds, C., Lencz, T., Scerbo, A., Triphon, N. and Kim, D. (1994) Cognitive-perceptual, interpersonal, and disorganized features of schizotypal personality. Schizophrenia Bulletin, 20, 191-201.

[5] Van Os, J. (2003) Is there a continuum of psychotic experiences in the general population? Epidemiologia $e$ Psichiatria Sociale, 12, 242-252.

[6] Raine, A. (1991) The SPQ: A scale for the assessment of schizotypal personality based on DSM-III-R criteria. Schizophrenia Bulletin, 17, 555-564.

[7] Chapman, L.J., Chapman, J.P., Kwapil, T.R., Eckblad, M.L. and Zinser, M.C. (1994) Putatively psychosis prone individuals ten years on. Journal of Abnormal Psychology, 103, 171-183. doi:10.1037/0021-843X.103.2.171

[8] Van Kampen, D. (2006) The Schizotypic Syndrome Questionnaire (SSQ): Psychometrics, validation and norms. Schizophrenia Research, 84, 305-322. doi:10.1016/j.schres.2006.02.011

[9] Gruzelier, J.H. (1996) The factorial structure of schizotypy: Part I. Affinities with syndromes of schizophrenia. Schizophrenia Bulletin, 22, 611-620.

[10] Lindenmayer, J.P., Grochowski, S. and Hyman, R.B. (1995) Five factor model of schizophrenia: Replication across samples. Schizophrenia Research, 14, 229-234. doi:10.1016/0920-9964(94)00041-6

[11] Mass, R., Schoemig, T., Hitschfeld, K., Wall, E. and Haasen, C. (2000). Psychopathological syndromes of schizophrenia: Evaluation of the dimensional structure of the positive and negative syndrome scale. Schizophrenia Bulletin, 26, 167-177. 
[12] El Yazaji, M., Battas, O., Agoub, M., Moussaoui, D., Gutknecht, C., Dalery, J., d' Amato, T. and Saoud, M. (2002) Validity of the depressive dimension extracted from principal component analysis of the PANSS in drugfree patients with schizophrenia. Schizophrenia Research, 56, 121-127. doi:10.1016/S0920-9964(01)00247-X

[13] Vollema, M.G., and Hoijtink H. (2000) The multidimensionality of self-report schizotypy in a psychiatric population: An analysis using multidimensional Rasch models. Schizophrenia Bulletin, 26, 565-575.

[14] Gassab, L., Mechri, A., Dumas, P., Saoud, M., d’ Amato, T., Dalery, J. and Gaha, L. (2006) Dimensional approach of schizotypal personality: A comparative study between French and Tunisian students. Annales Médico-Psychologiques, Revue Psychiatrique, 164, 377-382.

[15] Chen, W.J., Hsiao, C.K. and Lin, C.C.H. (1997) Schizotypy in community samples: The three-factor structure and correlation with sustained attention. Journal of $A b$ normal Psychology, 106, 649-654. doi:10.1037/0021-843X.106.4.649

[16] Fyers, A.J., Endicott, J., Manuzza, S., and Klein, D.F. (1985) Schedule for affective disorders and schizophrenia-life anxiety version. New York State Psychiatric Institute, New York.

[17] Dumas, P., Saoud, M., Bouafia, S., Gutknecht, C., Ecochard, R., Dalery, J., Rochet, T. and d' Amato, T. (2002) Cannabis use correlates with schizotypal personality traits in healthy students. Psychiatry Research, 109, 27-35. doi:10.1016/S0165-1781(01)00358-4

[18] Dumas, P., Daléry, J., Saoud, M. and d’ Amato, T. (1999a) Traductions et adaptations françaises des questionnaires d' idéation magique [MIS; Eckblad and Chapman 1983] et d' aberrations perceptives [PAS; Chapman et coll. 1978]. Encephale, 25, 422-428.

[19] Dumas, P., Bouafia, S., Gutknech, C., Saoud, M., Daléry, J. and d' Amato, T. (2000a) Validations des versions françaises des questionnaires d' idéation magique [MIS; Eckblad and Chapman 1983] et d' aberrations perceptives [PAS; Chapman et coll. 1978]. Encephale, 26, 42-46.

[20] Assouly-Besse, F., Dollfus, S. and Petit, M. (1995) Traduction française des questionnaires d' anhédonie sociale et physique de Chapman: Validation de la traduction française à partir de témoins et de patients schizophrènes. Encephale, 21, 273-284.

[21] Loas, G., Dubal, S. and Pierson, A. (1996). Dépistage de l' anhédonie chez le sujet sain: Détermination des notesseuils à l' échelle révisée d' anhédonie physique [PAS] de Chapman et Chapman [1978]. Encephale, 22, 298-302.

[22] Dumas, P., Rosenfeld, F., Saoud, M., Daléry, J. and d' Amato, T. (1999b) Traduction et adaptation française du questionnaire de parsonnalité schizotypique de raine
[SPQ]. Encephale, 25, 315-322.

[23] Dumas, P., Bouafia, S., Gutknecht, C., Saoud, M., Daléry, J. and d' Amato, T. (2000b) Validation de la version française du questionnaire de personnalité schizotypique de Raine [SPQ]—approche catégorielle et dimensionnelle des traits de personnalité schizotypique en population étudiante saine. Encephale, 26, 23-29.

[24] Bentall, R.P., Claridge, G.S. and Slade, P.D. (1989). The multi-dimensional nature of schizotypal traits: A factor analytic study with normal subjects. British Journal of Clinical Psychology, 28, 363-375. doi:10.1111/j.2044-8260.1989.tb00840.x

[25] Schiffman, J., Nakamura, B., Earleywine, M. and LaBrie, J. (2005). Symptoms of schizotypy precede cannabis use. Psychiatry Research, 134, 37-42. doi:10.1016/j.psychres.2005.01.004

[26] Vollema, M.G. and van den Bosch, R.J. (1995). The multidimensionality of schizotypy. Schizophrenia Bulletin, 21, 19-31.

[27] Battaglia, M., Cavallini, M.C., Macciardi, F. and Bellodi, L. (1997) The structure of DSM-III-R schizotypal disorder diagnosed by direct interviews. Schizophrenia Bulletin, 23, 1-10.

[28] Rossi, A. and Daneluzzo, E. (2002) Schizotypal dimensions in normals and schizophrenic patients: A comparison with other clinical samples. Schizophrenia Research, 54, 67-75. doi:10.1016/S0920-9964(01)00353-X

[29] Fossati, A., Raine, A., Carretta, I., Leonardi, B. and Maffei, C. (2003) The three-factor model of schizotypal personality: Invariance across age and gender. Personality and Individual Differences, 35, 1007-1019. doi:10.1016/S0191-8869(02)00314-8

[30] Suhr, J.A. and Spitznagel, M.B. (2001) Factor versus cluster models of schizotypal traits: I. A comparison of unselected and highly schizotypal samples. Schizophrenia Research, 52, 231-239. doi:10.1016/S0920-9964(00)00170-5

[31] Mason, O. and Claridge, G. (2006) The Oxford-Liverpool Inventory of Feelings and Experiences (O-LIFE): Further description and extended norms. Schizophrenia Research, 82, 203-211. doi:10.1016/j.schres.2005.12.845

[32] Rosenberger, P.H. and Miller, G.A. (1989) Comparing borderline definition: DSM-III borderline and schizotypal personality disorders. Journal of Abnormal Psychology, 98, 161-169. doi:10.1037/0021-843X.98.2.161

[33] Bergman, A.J., Harvey, P.D., Mitropoulou, V., Aronson, A., Marder, D., Silverman, J., Trestman, R. and Siever, L.J. (1996) The factor structure of schizotypal symptoms in a clinical population. Schizophrenia Bulletin, 22, 501509. 